\title{
Potential sexual addiction (PSA) among Men who have sex with men (MSM) who attended STD clinic, Kalubowila: A descriptive cross- sectional study
}

\author{
Perera PADMP ${ }^{1}$, Abeygunasekera $\mathrm{N}^{2}$, Gunewardhana $\mathrm{CU}^{2}$, Kumarasinghe $\mathrm{NH}^{1}$, Mohedeen $\mathrm{SB}^{2}$
}

\begin{abstract}
Introduction: Sex addiction is the inability to control sexual impulses resulting in continued sex related behaviors despite the negative consequences. This is the first study conducted on PSA among MSM in Sri Lanka.

Objective: To describe the prevalence of PSA and its associating factors among MSM who attend STD clinic, Kalubowila.

Method: A descriptive cross sectional study was conducted among 240 MSM clinic attendees for a period of 1 year, using the PATHOS screening tool via an interviewer administered questionnaire. PATHOS consists of six items found in both the Sexual Addiction Screening Test (SAST) and its revision, and the cut off value is 3. Data was analyzed by SPSS.

Result: The mean age of participants was 29.38 years (SD 9.7). Majority were unmarried, had male partners only and had 1 or more partners in last 3 months. A quarter was diagnosed with a new STD and among them, 3 were diagnosed with HIV. Eighty-two MSM had PATHOS cut off value, giving 34\% prevalence of PSA. Approximately $75 \%$ felt that their life was controlled by sexual desire, and $40 \%$ felt depressed following sex. Presence of PSA was not significantly associated with the presence of a $\operatorname{STD}(p=0.224623)$, sex of partners $(p=0.289935)$ or number of partners. However, PSA was significantly associated with behaviours such as insertive and receptive anal $\operatorname{sex}(\mathrm{p}=0.041046 \& \mathrm{p}=0.037916)$ and feeling depressed following a sexual act $(\mathrm{p}<0.00001)$.
\end{abstract}

Conclusion: PSA is high among MSM who attended this STD clinic which needs further psychosexual assessment.

Key words: Potential sexual addiction, MSM, PATHOS screening tool

Authors: ${ }^{1}$ Dr P.A.D.M.P. Perera (MBBS, PgDipVen, MD); Senior registrar in Venereologist, National STD/SACP. ${ }^{2}$ Dr N. Abeygunasekara (MBBS, PgDipVen, MD), Consultant Venereologist, STD clinic, Kalubowila, ${ }^{2} D r$ C. U. Gunewardhana,(MBBS, PgDipVen), MO/ STD, STD clinic, Kalubowila, ${ }^{1} \mathrm{Dr}$ NH Kumarasinghe (MBBS, PgDipVen, Registrar in Venereology), NSACP, ${ }^{2} \operatorname{Dr}$ S.B. Moheedeen (MBBS), MO/STD, STD clinic, Kalubowila

\section{Copyright}

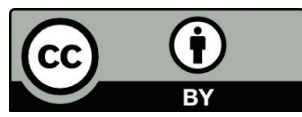

Corresponding author: ${ }^{1}$ Dr P.A.D.M.P. Perera, Email; piyumipp@gmail.com

Acknowledgement: All patients who took part in the research

Conflict of interest: No conflict of interest

Funding: No funding support for this study

Originality: This is an original work not published anywhere

Submitted on: 22.11.2018; Accepted on: 30.12.2018 


\section{Full article}

\section{Introduction}

Sex addiction is the inability to control sexual impulses resulting in continued engagement in sex related behaviors despite the creation of negative consequences. This term has been used synonymously with others, such as compulsive sexual behaviors, hypersexuality, and excessive sexual desire disorder. Compulsive sexual behaviors (CSB) can present in a variety of forms and degrees of severity, much like that of substance use disorders, mood disorders, or impulse-control disorders. One of the fundamental hallmarks of compulsive sexual behavior is continued engagement in sexual activities despite the negative consequences created by these activities. Though the presence of sexually transmitted diseases do not necessarily indicate compulsive sexual activity, their presence signal the need to screen for those behaviours. Furthermore, as a consequence of these behaviours, patients are at a higher risk for acquiring sexually transmitted diseases (STDs) and for physical injuries due to repetitive sexual practices. Human immunodeficiency virus (HIV), Hepatitis B and C, syphilis, and gonorrhea are particularly concerning consequences.(1)

Although no large epidemiological studies have been performed, the estimated prevalence rate of CSB is approximately $3-6 \%$ in USA. Due to the sensitive nature of sex behavior, however, many have argued that the prevalence of CSB may be underreported in the general population and that females may be underrepresented in these clinical samples.(2) Higher rates have been suggested in specific populations such as sexual offenders and HIV patients.(3)

There are several validated tools to screen for sex addiction which are being currently used. The most commonly used tool is SAST-R (Sexual addiction screening test - revised) which comprises of 45 questions. A shorter screening tool named PATHOS was recently validated as well in USA.(4) PATHOS is named after Greek word pathos which is for "suffering". It comprises of 6 questions and is a quick screening instrument for the detection of potential sexual addiction. PATHOS is scored in a "yes", "no" format with 3 or more "yes" responses indicating that the sexual behavior is problematic.(5)

This instrument has demonstrated to have $88.3 \%$ sensitivity, and $81.6 \%$ specificity for differentiating between male addicts and non-addicts. Second phase results showed similar effectiveness of the instrument in the female population achieving $80.9 \%$ sensitivity and $87.2 \%$ specificity when classifying clients from healthy volunteers.(6) It has an internal consistency alpha range from 0.77 to 0.94 which suggest good reliability.(7) This tool has been used in this study as the study instrument due to its' simplicity.

The objective of this study was to determine the prevalence of potential sex addiction among Males who have Sex with Males (MSM) who attend STD clinic, Kalubowila

\section{Method}

This was a descriptive cross-sectional study conducted in the STD clinic Kalubowila over a period of one year, among MSM clinic attendees. A sample of 240 MSM were included in this study. Data was collected using an interviewer administered questionnaire which comprised of the 6 PATHOS questions, socio demographic data and sexual practices. Well trained doctors administered the questionnaire. Data on the presence of STI were collected from the clinic records of the study participants using separate data extraction sheets. Ethical clearance was obtained from the ERC NHSL and data was analysed using SPSS.

Results

\section{Socio demographic data}

The age of the study sample ranged from $15-62$ years and nearly $40 \%$ belonged to the age group of $20-25$ years. Five participants were in the 15-19 years age group. Majority (88\%) were unmarried and had secondary education and above. Around $20 \%$ did not have a monthly income.

\section{Sexual behaviours}

Majority (58.75\%) of the MSM had only male sexual partners and rest had both male and female partners during their lifetime. Number of sexual partners in the last 3 months ranged from $0-30$ and majority (90.8\%) had less than 5 partners during the last 3 months. When the number of lifetime partners are considered, nearly half (48\%) had $11-100$ partners.

The study sample practised full range of sexual acts and majority (79\%) engaged in insertive peno oral sex followed by insertive peno anal sex (75\%). The percentages of receptive sexual practises were $68 \%$ (peno oral) and 61\% (peno anal) among this study 
sample. Close to $40 \%$ engaged in peno vaginal sex as well.

Table 1: Age distribution of the study sample $(n=240)$

\begin{tabular}{|c|c|}
\hline Age group & Percentage \\
\hline $15-19$ & $6.3 \%$ \\
\hline $20-25$ & $39.6 \%$ \\
\hline $26-30$ & $19.6 \%$ \\
\hline $31-35$ & $12.1 \%$ \\
\hline $36-40$ & $9.6 \%$ \\
\hline $41-45$ & $5.0 \%$ \\
\hline $46-50$ & $2.9 \%$ \\
\hline $51-55$ & $2.5 \%$ \\
\hline $56-60$ & $1.7 \%$ \\
\hline $61-65$ & $0.8 \%$ \\
\hline
\end{tabular}

Figure 1: Marital status of the study sample

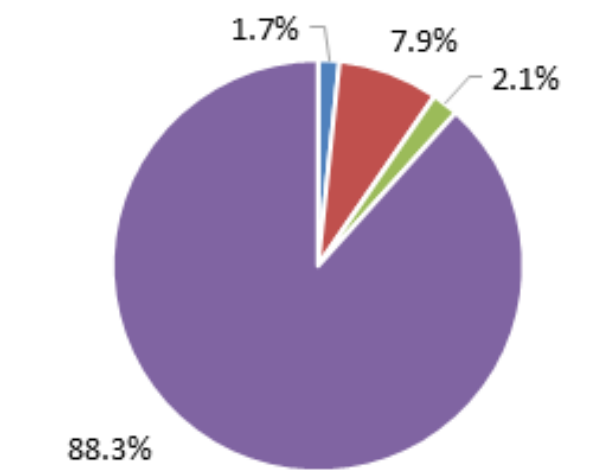

- divorced = married $\mid$ seperated = unmarried

Table 2: Number of sexual partners during last 3 months, 1 year and lifetime $(n=240)$

\begin{tabular}{lrrr}
$\begin{array}{l}\text { Number of } \\
\text { partners }\end{array}$ & 3 months & 1 year & Lifetime \\
$<5$ & 218 & 132 & 53 \\
\hline $6-10$ & 16 & 69 & 54 \\
\hline $11-100$ & 6 & 38 & 115 \\
\hline$>100$ & 0 & 1 & 18 \\
\hline
\end{tabular}

\section{Presence of a STI}

In this study group, 58 (24.1\%) participants were diagnosed with STI and among them 3 were diagnosed with HIV. Commonest STIs diagnosed were genital warts $(n=18)$, late syphilis $(n=11)$, non gonoccal urethritis $(n=9)$ and genital herpes $(n=8)$. Six participants had 2 or more STI diagnoses.
Figure 2: Type of partners for lifetime $(n=240)$

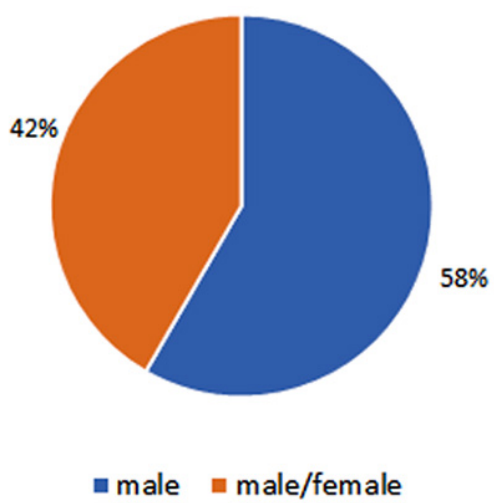

Table 3: Sexual practices of the study sample during lifetime $(n=240)$

\begin{tabular}{lrr} 
Sexual practice & Yes (\%) & No (\%) \\
Per vaginal & 39 & 61 \\
\hline Insertive P-A & 75 & 25 \\
\hline Receptive P-A & 61 & 39 \\
\hline Insertive P-O & 79 & 21 \\
\hline Receptive P-A & 68 & 32 \\
\hline
\end{tabular}

Figure 3: Number and types of STD diagnoses among the MSM clinic attendees $(\mathrm{N}=58)$

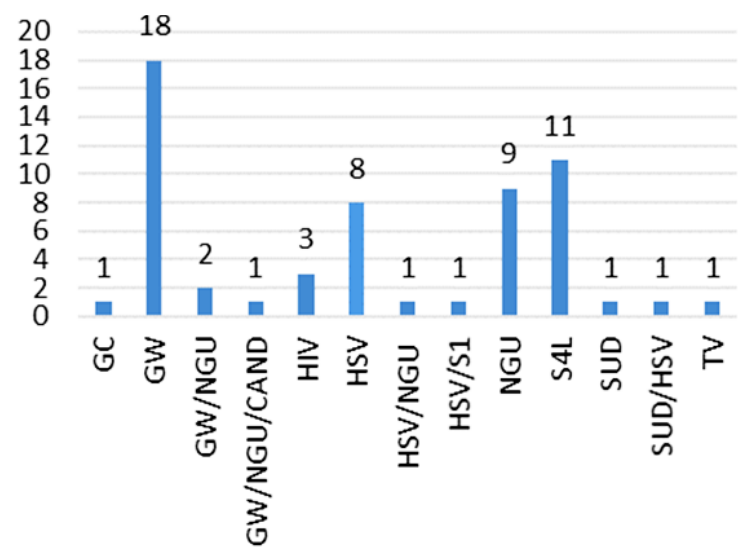

\section{Response to the PATHOS questionnaire}

The PATHOS questionnaire consisted of 6 questions and the answers were in "yes" or "no" format. (Table 4). Out of the 6 questions majority (71.6\%) gave yes answers to the question - "Do you hide some of your sexual behaviors from others?". Only 10.9\% answered yes to "Have you ever sought therapy for sexual behavior you did not like?" 
Using the PATHOS screening tool, prevalence of potential sexual addiction was calculated. A score of three or more "yes" answers were considered as having PSA. Therefore, according to this tool, the prevalence of PSA among this study group was $34 \%$.

Table 4: Variables in the PATHOS screening tool

\begin{tabular}{ll} 
Category & Question \\
Preoccupation & $\begin{array}{l}\text { Do you often find yourself preoccupied } \\
\text { with sexual thoughts? }\end{array}$ \\
\hline Ashamed & $\begin{array}{l}\text { Do you hide some of your sexual } \\
\text { behaviours from others? }\end{array}$ \\
\hline Treatment & $\begin{array}{l}\text { Have you ever sought therapy for sexual } \\
\text { behaviour you did not like? }\end{array}$ \\
\hline Hurt others & $\begin{array}{l}\text { Has anyone been hurt emotionally } \\
\text { because of your sexual behaviors? }\end{array}$ \\
\hline Out of control & $\begin{array}{l}\text { Do you feel controlled by your sexual } \\
\text { desire? }\end{array}$ \\
\hline Sad & $\begin{array}{l}\text { When you have sex, do you feel } \\
\text { depressed afterwards? }\end{array}$
\end{tabular}

Figure 4: Responses for the PATHOS screening tool $(n=240)$

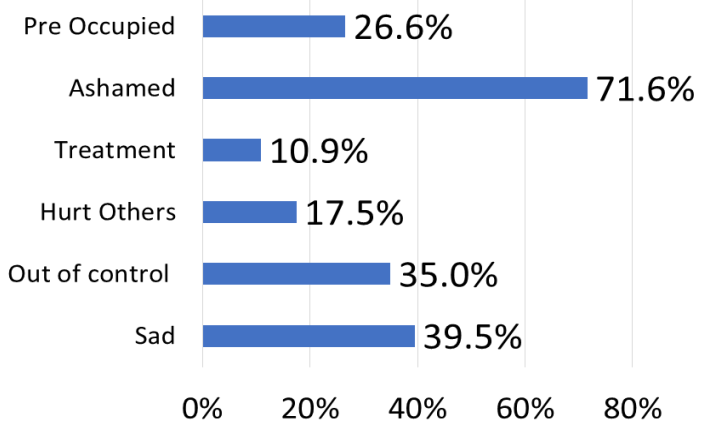

Figure 5: Total scores for the PATHOS screening tool among MSM clinic attendees

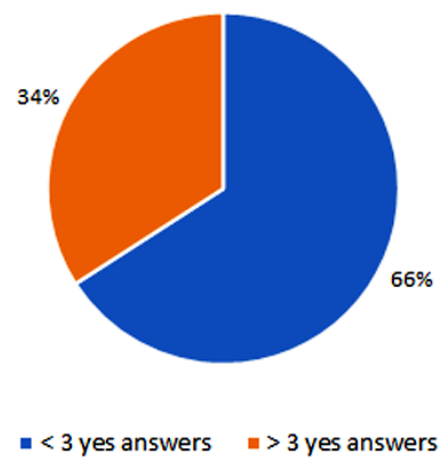

Significant associations

Significant associations were calculated using chi square and fisher exact test. Potential sexual addiction was significantly associated with insertive as well as receptive anal sexual practices. ( $\mathrm{p}=0.041046$ and 0.037916 respectively)

Table 5: PSA and insertive anal sexual practices

\begin{tabular}{lcr} 
& Insertive Anal sex & \\
PSA & Yes & No \\
Yes & 68 & 14 \\
\hline No & 112 & 46 \\
\hline
\end{tabular}

Table 6: PSA and receptive anal sexual practices

\begin{tabular}{lcr} 
& ReceptiveAnal sex & \\
PSA & Yes & No \\
Yes & 57 & 25 \\
\hline No & 88 & 70
\end{tabular}

The results were significant at $\mathrm{p}<0.05$.

Potential sexual addiction was not significantly associated with presence of a STI $(\mathrm{p}=0.224623)$, type of partners $(\mathrm{p}=0.289935)$, number of partners during last 3 months $(\mathrm{p}=0.609), 1$ year $(\mathrm{p}=0.631)$ or life time $(\mathrm{p}=0.270)$.

\section{Reliability of PATHOS screening tool}

As this screening tool was adopted from studies done in the western countries, Cronbach's alpha testing was used to find out the reliability in this setting. The value was 0.393 and suggests that the reliability is low in this setting. It is considered reliable when this value is 0.7 or above. In a country like Sri Lanka where MSM are stigmatized it is not surprising that over $70 \%$ feel ashamed. Therefore, the use of PATHOS in Sri Lanka is questionable.

\section{Discussion}

This is the first study ever conducted to see the prevalence of potential sexual addiction in Sri Lanka among MSM clinic attendees in STD clinic Kalubowila. In an anonymous, cross sectional study done among MSMs in New York in 2003 and 2004, $19.3 \%$ showed symptoms of sexual compulsivity. (8) It highlighted the importance of this area for further research.

The majority of the study sample were young MSM who had purely male partners and were unmarried. Even though majority had secondary education and above, they had a high partner turnover with lifetime partner numbers going up to one hundred. Furthermore, they had a range of high risk sexual 
practices like receptive anal sex. Therefore, they are at a high risk of acquiring STIs including HIV. Almost one quarter of this study group had a STI diagnosis and three were HIV positive which indicated that this group was a high risk group. It is important to assess the psycho sexual reasons for such high-risk behaviours as the HIV sero surveillance done in Sri Lanka (2016) showed rising HIV among MSM.(9) By assessing any contributory psycho sexual factors, prevention methods can be strengthened in regards to STI and HIV.

In this study population the prevalence of PSA was $34 \%$. It was significantly associated with the insertive and receptive sexual practices. But it was not significantly associated with presence of a STI, type of partners, number of partners during last 3 months, 1 year and life time. But in a study done in Indiana, USA, using sexual compulsivity scale(SCS), they found out that men who scored high on the SCS were significantly more likely to have been diagnosed with STI than other men. (10) Furthermore, the study done in New York among MSM, sexual compulsivity was bivariately associated with being HIV positive and reporting unprotected anal intercourse. (8)

The PATHOS screening tool had shown an internal consistency alpha range from 0.77 to 0.94 which suggest good reliability ${ }^{(7)}$ in studies done in USA. However, in this study the internal consistence was only 0.393 . This may be due to the fact that the questions were translated in to Sinhala language and as a result the participant's understanding of the questions may have been affected. Therefore, further pre testing of this tool may be needed with more adjustments.

\section{Conclusions}

The sample of the MSM population in this study showed high risk behaviour which put them at risk for acquiring STIs and HIV. Furthermore, they had significant prevalence of STIs and HIV. Using the PATHOS screening tool, a high prevalence of potential sexual addiction was detected among them which needs further methodical psycho sexual assessment and as in other studies, this population had a significant association between PSA and engaging in anal sexual practices. Though this screening tool consisted only 6 questions and is easy to administer, the reliability in this setting is low, therefore more pretesting and making necessary adjustments are needed if it is to be used in further studies to assess potential sexual addiction.

\section{References}

1. Fong TW. Understanding and Managing Compulsive Sexual Behaviors. Psychiatry (Edgmont). 2006 Nov; 3(11): https://www.ncbi.nlm.nih.gov/pmc/articles/ PMC2945841/ (accessed 29 March 2017).

2. Derbyshire KL, Grant JE. Compulsive sexual behavior: A review of the literature. Journal of Behavioral Addictions May 27, 2015; 4(2). https://www.ncbi.nlm.nih.gov/pmc/ articles/PMC4500883/ (accessed 29 March 2017).

3. Garcia FD, Thibaut F. Sexual addictions. The American Journal of Drug and Alcohol Abuse 2010; 36. http:// www.aius.fr/v2/data/Thematiques/sexologieclinique/

4. Dawson GN, Warren DE. Evaluating and Treating Sexual Addiction. American Family Physician 2012; 86(1). http://www.aafp.org/afp/2012/0701/p74.html (accessed 29 March 2017).

5. Carnes PJ, Green BA, Merlo LJ, Polles A, Carnes S, Gold MS. PATHOS: A brief screening application for assessing sexual addiction. Journal of addiction medicine 2012; 6(1). https://www.ncbi.nlm.nih.gov/pmc/articles/ PMC3212607/ (accessed 29 March 2017).

6. Quizlet Inc. Sex addiction. https:/quizlet.com/47933596/ sex-addiction-flash-cards/ (accessed 30 March 2017).

7. Karila L, Wéry A, Weinstein A, Cottencin O, Petit A, Reynaud M, Billieux J. Sexual addiction or hypersexual disorder: different terms for the same problem? A review of the literature. Current pharmaceutical design 2014; 20(25). https://www.ncbi.nlm.nih.gov/ pubmed/24001295 (accessed 29 March 2017).

8. Parsons JT, Grov C, Golub SA. Sexual compulsivity, co-occurring psychosocial health problems, and HIV risk among gay and bisexual men: further evidence of a syndemic.. American Journal of Public Health 2012;102(1). https://www.ncbi.nlm.nih.gov/ pubmed/22095358 (accessed 29 March 2017).

9. Strategic Information Management unit, NSACP. Annual report 2016, National STD/ AIDS Control Programme. Sri Lanka: NSACP; 2017. http:// www.aidscontrol.gov.lk/index.php? option $=$ com content\&view=article\&id=19\&Itemid=139\&lang=en (accessed 15 November 2018)

10. Dodge B, Reece M, Herbenick D, Fisher C, Satinsky S, Stupiansky N. Relations between sexually transmitted infection diagnosis and sexual compulsivity in a community-based sample of men who have sex with men. Sexually transmitted infections 2008; 84(4). https:// www.ncbi.nlm.nih.gov/pubmed/18096648 (accessed 30 March 2017). 